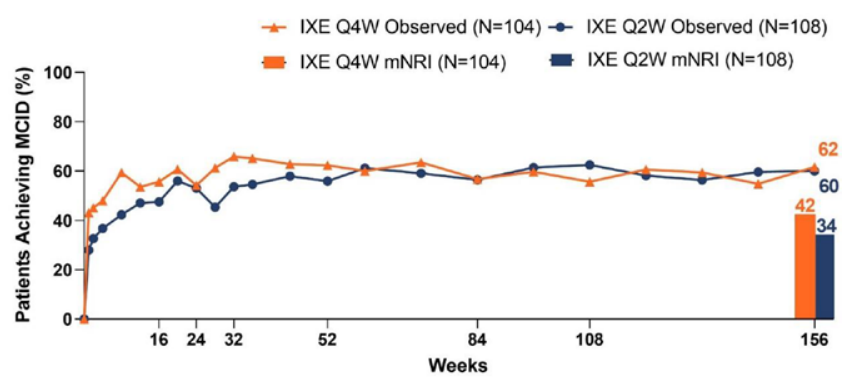

Figure 2. Patients achieving HAQ-DI MCID Response up to Week 156 (Observed) and at Week 156 (mNRI) among patients with HAQ-DI $\geq 0.35$ at baseline: Intent-to-Treat Population (Patients Randomized to IXE at Baseline)

Conclusion: Improvements in PROs, measuring physical and mental function, quality of life, and work productivity are maintained up to 3 years with IXE treatment in patients with active PsA who have had an inadequate response or intolerance to 1 or 2 TNFis.

References:

[1] Nash P, et al. Lancet. 2017;389(10086):2317-2327.

[2] Genovese MC, et al. Rheumatology (Oxford). 2018;57(11):2001-2011.

Disclosure of Interests: Ana-Maria Orbai Grant/research support from: Abbvie, Eli Lilly and Company, Celgene, Novartis, Janssen, Horizon, Consultant of: Eli Lilly; Janssen; Novartis; Pfizer; UCB. Ana-Maria Orbai was a private consultant or advisor for Sun Pharmaceutical Industries, Inc, not in her capacity as a Johns Hopkins faculty member and was not compensated for this service., Jordi Gratacos-Masmitja Grant/research support from: a grant from Pfizzer to study implementation of multidisciplinary units to manage PSA in SPAIN, Consultant of: Pfizzer, MSD, ABBVIE, Janssen, Amgen, BMS, Novartis, Lilly, Speakers bureau: Pfizzer, MSD, ABBVIE, Janssen, Amgen, BMS, Novartis, Lilly, Eva Dokoupilova Grant/research support from: Eli Lilly and Abbvie, Bernard Combe Grant/research support from: Novartis, Pfizer, Roche-Chugai, Consultant of: AbbVie; Gilead Sciences, Inc.; Janssen; Eli Lilly and Company; Pfizer; Roche-Chugai; Sanofi, Speakers bureau: Bristol-Myers Squibb; Gilead Sciences, Inc.; Eli Lilly and Company; Merck Sharp \& Dohme; Pfizer; Roche-Chugai; UCB, Arnaud Constantin Grant/research support from: Study was sponsored by Sanofi Genzyme, Consultant of: Consulting fees from Abbvie, BMS, Celgene, Gilead, Janssen, Lilly, Novartis, Pfizer, Roche, Sanofi, UCB, Amanda M. Gellett Shareholder of: Eli Lilly and company, Employee of: Eli Lilly and company, Aubrey Trevelin Sprabery Shareholder of: Eli Lilly and Company, Employee of: Eli Lilly and Company, Julie Birt Shareholder of: Eli Lilly and Company, Employee of: Eli Lilly and Company, Vladimir Geneus Shareholder of: Eli Lilly and Company, Employee of: Eli Lilly and Company, Peter Nash Grant/research support from: AbbVie, Bristol-Myers Squibb, Celgene, Eli Lilly and Company, Gilead, Janssen, MSD, Novartis, Pfizer Inc, Roche, Sanofi, UCB, Consultant of: AbbVie, Bristol-Myers Squibb, Celgene, Eli Lilly, Gilead, Janssen, MSD, Novartis, Pfizer Inc, Roche, Sanofi, UCB, Speakers bureau: AbbVie, Bristol-Myers Squibb, Celgene, Eli Lilly, Gilead, Janssen, MSD, Novartis, Pfizer Inc, Roche, Sanofi, UCB DOI: 10.1136/annrheumdis-2020-eular.2087

\section{AB0815 CHANGES IN BODY COMPOSITION, BONE MINERAL DENSITY AND BONE REMODELING MARKERS DURING INTERLEUKIN 12/23 INHIBITION IN PSORIATIC ARTHRITIS}

J. Paccou ${ }^{1}$, W. Bavière ${ }^{1}$, R. Chapurlat ${ }^{2}$, E. Sornay-Rendu' ${ }^{2}$, P. Szulc ${ }^{2}$, B. Cortet ${ }^{1}$, R. M. Flipo ${ }^{1} .{ }^{1}$ Lille University Hospital, Lille, France; ${ }^{2}$ Lyon University Hospital, Lyon, France

Background: Psoriatic arthritis (PsA) is a chronic inflammatory disease characterized by multiple comorbid conditions including cardiovascular comorbidities, diabetes, obesity and osteoporosis. Little is known about body composition in patients with PsA and no data are available regarding body composition changes under DMARDs. Objectives: We investigated the effects of ustekinumab (UST), a humanized anti-interleukin 12/23 antibody, on body composition, bone mineral density (BMD) and bone remodeling markers in patients treated for PsA.

Methods: Thirty patients with active PSA treated with UST were included in a 6 months open follow-up study. Body mass index, DAS28-CRP, bone remodeling markers, serum levels of leptin, BMD and body composition (dual-energy X-ray absorptiometry) were measured at baseline and 6 months of treatment. At baseline, PsA patients were compared with 60 non-PsA controls matched for age, sex and body mass index.

Results: Compared with controls, we observed lower total and appendicular lean mass $(53.1 \pm 13.1$ vs. $56.7 \pm 11.9 \mathrm{~kg}, p=0.013$ and $21.6 \pm 6.3$ vs. $23.4 \pm 5.0 \mathrm{~kg}$, $p=0.010$ respectively) and greater fat mass in PsA (32.5 \pm 10.8 vs. $25.2 \pm 8.9 \mathrm{~kg}$, $\mathrm{p}<0.001$ ). Among PsA patients, $30 \%$ had a skeletal muscle mass index below the cut-off point for sarcopenia (Baumgartner's criteria: men $7.26 \mathrm{~kg} / \mathrm{m} 2$, women $5.5 \mathrm{~kg} / \mathrm{m} 2$ ) whereas no case was observed in the control group. After 6 months of treatment with UST, there was not a significant change of BMI, while there was a tendency for reaching the significant level for fat mass $(+1.75 \pm 3.60 \mathrm{~kg}, p=0.054)$, and fat mass index $\left(+0.59 \pm 1.25 \mathrm{~kg} / \mathrm{m}^{2}, \mathrm{p}=0.061\right)$. In contrast, a decrease in total lean mass was observed $(-1.57 \pm 3.10 \mathrm{~kg}, \mathrm{p}=0.046)$ without a significant change in appendicular lean mass and skeletal muscle mass index. No changes for bone remodeling markers, leptin and BMD were observed at 6 months.

Conclusion: Patients with active PsA required biologic therapy had increased fat mass and decreased lean mass. Moreover, ustekinumab might worsen the decrease in lean mass with no significant change in fat mass.

Disclosure of Interests: Julien Paccou Grant/research support from: Janssen, Speakers bureau: Abbvie, Amgen, Janssen, Lilly, MSD, Novartis, Pfizer, Sandoz, Sanofi, UCB, Wallis Bavière: None declared, Roland Chapurlat: None declared, Elisabeth Sornay-Rendu: None declared, Pawel Szulc: None declared, Bernard Cortet Consultant of: Aptissen, René-Marc Flipo Consultant of: Johnson and Johnson, MSD France, Novartis, Sanofi, Speakers bureau: Johnson and Johnson, MSD France, Novartis, Sanofi

DOI: 10.1136/annrheumdis-2020-eular.3176

\section{$\mathrm{AB} 0816$}

\section{CARDIOVASCULAR COMORBIDITIES IN PSORIATIC} ARTHRITIS: A CASE CONTROL STUDY.

D. Á. Galarza-Delgado ${ }^{1}$, J. R. Azpiri-López ${ }^{2}$, I. J. Colunga-Pedraza ${ }^{1}$, A. Pérez Villar $^{1}$, I. C. Zárate Salinas ${ }^{2}$, P. F. Frausto Lerma ${ }^{1}$, M. A. Reyes Soto ${ }^{1}$, D. E. Flores Alvarado ${ }^{1}$, O. Ilizaliturri Guerra ${ }^{1}{ }^{1}$ Hospital Universitario Dr. José Eleuterio González, Rheumatology department, Monterrey, Mexico; ${ }^{2}$ Hospital Universitario Dr. José Eleuterio González, Cardiology Department, Monterrey, Mexico

Background: Psoriatic Arthritis (PsA) is an inflammatory arthritis associated with psoriasis. It occurs in approximately $8 \%-30 \%$ of patients diagnosed with psoriasis. In addition to joint and skin manifestations, patients with PsA have an increased prevalence of traditional cardiovascular (CV) risk factors that has been associated with a higher severity of PsA and increased cardiovascular disease (CVD). However, this increased risk has been attributed not only to increased traditional risk factors but also to chronic systemic inflammation.

Objectives: To compare the most relevant $\mathrm{CV}$ comorbidities in patients with PsA and controls.

Methods: A cross-sectional observational study was designed, 94 patients between 45-75 years who fulfilled the CASPAR classification criteria for PsA and 94 age-matched controls were included. The clinical characteristics compared between groups were: age, BMI, waist/hip index, gender, diabetes mellitus, hypertension, dyslipidemia, overweight, obesity, smoking history and prior cardiovascular event. Student-t test, Mann-Whitney $U, \mathrm{Chi}^{2}$ test and Fisher's exact test were used to compare data and odds ratio were calculated. $p \leq 0.05$ was considered statistically significant. Logistic regression analysis was used to test association between significant clinical risk factors for PsA. The data were analyzed using the SPSS version 25 software.

Results: 94 PsA patients and 94 controls were included. The majority of the patients were women (57.4\% in the PsA group and $80.9 \%$ in the control group) ( $p$ $0.001)$. Body mass index and waist/hip index were higher in PsA group ( $p 0.002)$ $(p<0.001)$ respectively.

PsA patients had more hypertension than controls $(p 0.022)$, more overweight $(p 0.005)$, and a higher smoking history $(p<0.001)$ than the control group. There was a trend in higher hyperlipidemia prevalence in PsA patients (Table 1).

Table 1. Clinical comorbidities and risk factors for PsA.

\begin{tabular}{lcccc}
\hline Variable & PsA & Control & $p$ & OR $(95 \% \mathrm{Cl})$ \\
\hline Age $^{*}$ & $53.23 \pm 11.31$ & $53 \pm 10$ & 0.790 & \\
BMI $^{*}$ & $29.37 \pm 5.32$ & $27.21 \pm 4.17$ & 0.002 & \\
Waist/Hip Index & $0.94(0.88-1.03)$ & $0.90(0.85-0.92)$ & $<0.001$ & \\
Gender & & & 0.001 & \\
Female & $54(57.4 \%)$ & $76(80.9 \%)$ & & \\
Male & $40(42.6 \%)$ & $18(19.1 \%)$ & & \\
Diabetes & $18(19.1 \%)$ & $14(14.9 \%)$ & 0.438 & $1.35(0.62-2.91)$ \\
Hypertension & $33(35.1 \%)$ & $19(20.2 \%)$ & 0.022 & $2.13(1.10-4.12)$ \\
Dyslipidemia & $36(38.3 \%)$ & $24(25.5 \%)$ & 0.06 & $1.81(0.97-3.37)$ \\
Overweight & $77(81.9 \%)$ & $60(63.8 \%)$ & 0.005 & $2.56(1.31-5.03)$ \\
Obesity & $36(37.6 \%)$ & $26(27.7 \%)$ & 0.146 & $1.57(0.85-2.92)$ \\
Smoking history & $36(38.3 \%)$ & $78(83 \%)$ & $<0.001$ & $0.127(0.06-0.25)$ \\
History of CVD & $68(72.3 \%)$ & $8(53.3 \%)$ & 0.137 & $2.28(0.75-6.94)$ \\
\hline
\end{tabular}

${ }^{*}$ Data are reported in mean $\pm \mathrm{SD}$

${ }^{\star *}$ Data is reported in median (IQR) 